\title{
Estudo das briófitas do Bosque Sagrado da Guarita, Bom Princípio do Piauí, Piauí,
}

\section{Brasil}

\author{
Study of bryophytes of the Bosque Sagrado da Guarita, Bom Princípio of Piauí, Piauí, Brazil \\ Estudio de briófitas del Bosque Sagrado da Guarita, Bom Princípio do Piauí, Piaú, Brasil
}

Recebido: 01/03/2021 | Revisado: 06/03/2021 | Aceito: 23/04/2021 | Publicado: 08/05/2021

José Claudio Veras dos Santos

ORCID: https://orcid.org/0000-0003-3934-1155

Universidade Federal do Delta do Parnaíba, Brasil

E-mail: claudio_bio2012@hotmail.com

Hermeson Cassiano de Oliveira

ORCID: https://orcid.org/0000-0002-1611-9562

Universidade Estadual do Piaú, Brasil

E-mail: hermeson123@gmail.com

Maria Helena Alves

ORCID: https://orcid.org/0000-0003-0587-5546

Universidade Federal do Delta do Parnaíba, Brasil

E-mail: malves@ufpi.edu.br

\begin{abstract}
Resumo
O presente trabalho refere-se ao estudo da brioflora ocorrente no Bosque Sagrado da Guarita, Bom Princípio do Piauí, onde a flora briofítica, em termos de critério de identificação taxonômica, estava até então desconhecida. Para este estudo, foram realizadas oito coletas em 2016, sendo cinco concentradas no período chuvoso (fevereiro-abril) e três no período de estiagem (julho-setembro). Foram coletadas 51 amostras e identificadas 12 espécies de briófitas, dentre as quais duas são hepáticas: Riccia brasiliensis e R. fruchartii e 10 musgos: Archidium ohiense, Calymperes palisotii, Entodontopsis leucostega, Fissidens amoenus, F. angustifolius, F. guianensis. var. guianensis, F. zollingeri, Hyophiladelphus agrarius, Hyophila involuta e Octoblepharum albidum. Dentre as seis famílias ocorrentes na área, Fissidentaceae foi mais representativa, com quatro espécies. Ocorreu predominância do substrato rupícola. Estão sendo fornecidos chave de identificação, descrições, ilustrações e dados de distribuição geográfica. Este estudo vem contribuir com a divulgação das briófitas para o Brasil, além de trazer uma nova citação para o brioflora do Piauí.
\end{abstract}

Palavras-chave: Brioflora; Musgos; Novas ocorrências.

\begin{abstract}
The present work refers to the study of the bryoflora occurring in Guarita Sacred Forest, Bom Princípio do Piauí, where the bryophyte flora, in terms of taxonomic identification criteria, was previously unknown. For this study, eight collections were carried out in 2016, five of which were concentrated in the rainy season (February-April) and three in the dry season (July-September). 51 specimens were collected and 12 species of bryophytes were identified, among which two are hepatic: Riccia brasiliensis and R. fruchartii and 10 mosses: Archidium ohiense, Calymperes palisotii, Entodontopsis leucostega, Fissidens amoenus, F. angustifolius, F. guianensis var. guianensis, F. zollingeri, Hyophiladelphus agrarius, Hyophila involuta and Octoblepharum albidum. Among the six families in the area, Fissidentaceae was more representative, with four species. There was predominance of the rock substrate. Identification keys, descriptions, illustrations and geographic distribution data are being provided. This study contributes to the dissemination of bryophytes to Brazil, as well to bring three new citations to the bryophylla of Piauí. Keywords: Bryoflora; Mosses; New events.

\section{Resumen}

El presente trabajo se refiere al estudio de la bryoflora presente en el Bosque Sagrado da Guarita, Bom Princípio do Piauí, donde la flora briofítica, en términos de criterios de identificación taxonómica, era desconocida hasta entonces. Para este estudio se realizaron ocho recolecciones en 2016, cinco de las cuales se concentraron en la época de lluvias (febrero-abril) y tres en la época seca (julio-septiembre). Se recolectaron 51 muestras y se identificaron 12 especies de briófitas, dos de las cuales son hepáticas: Riccia brasiliensis y R. fruchartii y 10 musgos: Archidium ohiense, Calymperes palisotii, Entodontopsis leucostega, Fissidens amoenus, $F$. angustifolius, $F$. guianensis var. guianensis, $F$. zollingeri, Hyophiladelphus agrarius, Hyophila involuta y Octoblepharum albidum. Entre las seis familias presentes en el área, Fissidentaceae fue más representativa, con cuatro especies. Predominó el sustrato rupícola. Se proporcionan claves de identificación, descripciones, ilustraciones y datos de distribución geográfica. Este estudio contribuye a la diseminación de las briofitas a Brasil, además de traer una nueva cotización para la brioflora de Piauí.

Palabras clave: Bryoflora; Musgos; Nuevas apariciones.
\end{abstract}




\section{Introdução}

A diversidade de briófitas no mundo é expressada em cerca de 18.000 espécies, sendo que os Neotrópicos apresentam uma das mais ricas briofloras, com aproximadamente 4.000 espécies, distribuídas em 120 famílias e 595 gêneros (Gradstein et al., 2001). Destas, 1524 espécies, distribuídas em 413 gêneros e 117 famílias ocorrem no Brasil, sendo cerca de 298 consideradas como espécies endêmicas do país (Costa \& Peralta, 2015).

Estudos que registram a riqueza de flora briofítica piauiense ainda são escassos. Dentre as principais publicações que contribuem para o conhecimento da brioflora do Piauí, destaca-se Castro et al. (2002), que fizeram o levantamento das briófitas do Parque Nacional de Sete Cidades, Piauí e registraram 11 famílias com 22 espécies colonizando os substratos rupícola e corticícola, sendo 16 espécies consideradas novas ocorrências para o Estado.

Outro trabalho de grande importância para o Estado foi o de Brito et al. (2008), o qual constitui-se um dos primeiros com enfoque apenas no Piauí. Neste, os autores mencionam nove famílias e nove gêneros com 12 espécies, das quais 11 pertencem ao filo Bryophyta e uma ao filo Marchantiophyta, permanecendo o Piauí, sem registro do Filo Anthocerotophyta, mesmo assim os resultados constam de sete novas ocorrências para o estado do Piaúi. Os autores acrescentam que o substrato predominante das espécies foi corticícola e rupícola.

Em ambos os trabalhos, Castro et al. (2002) e Brito et al. (2008) ressaltaram a escassez de estudos sobre briófitas para o Piauí e os mesmos autores destacaram que deixaram suas contribuições, considerando o ano de 1922 como precursor dos estudos briológicos no Estado, resultando na citação de 11 espécies. Ainda segundo os autores, após a década de 20, houve um período estacionário e entre 1980 a 1992 ocorreu a elevação de mais três espécies, totalizando o registro de 14 diferentes táxons ocorrentes no Piauí.

Outros trabalhos que não se dedicam apenas ao Piauí, mas que já contribuíram bastante para o conhecimento acerca de sua brioflora foram: Peralta e Vital (2006), que citaram duas espécies, Câmara (2008), citando cinco espécies, Yano et al. (2009), citando 28 espécies, Oliveira e Bastos (2010), citando duas espécies e Yano (2010), relacionando 14 espécies em seu "Levantamento de Novas Ocorrências de Briófitas Brasileiras".

Costa e Peralta (2015), relacionam 1524 espécies para o Brasil, citando 689 espécies para o Nordeste e, dentre estas últimas, 50 espécies são para o estado do Piauí. Assim, os resultados recentes demonstram que o Piauí está despontando na briologia.

Nos últimos dois anos, novos trabalhos concentrados no território do Piaú acrescentaram ótima contribuição de espécies de briófitas à flora piauiense, como pode ser destacado em Nascimento et al. (2020), com adição de 34 espécies; Silva et al. (2019) que citaram 18 espécies; Sousa et al. (2019) que relataram 14 espécies; Gomes et al. (2019) ressaltando nove novas espécies a brioflora do estado e mais recentemente, Araújo et al. (2021) que somaram mais dois novos táxons, num total de 77, juntamente a este trabalho somam 78 novos registros para o estado do Piauí.

Neste aspecto, visando a ampliação do conhecimento acerca da brioflora do estado do Piauí, este trabalho objetivou realizar o estudo e identificação das espécies ocorrentes no Bosque Sagrado da Guarita, Bom Princípio do Piauí, norte do Estado, relacionando as espécies aos seus respectivos substratos e sua representatividade local.

\section{Metodologia}

A região objeto de estudo, conhecida como Bosque Sagrado da Guarita $\left(03^{\circ} 12^{\prime} 27 S^{\prime \prime}\right.$ e $\left.41^{\circ} 36^{\prime} 24 O^{\prime \prime}\right)$, está situada a cerca de $6 \mathrm{~km}$ da cidade de Bom Princípio do Piauí, em um pequeno povoado da zona rural, chamado Barrocas. O local possui uma área total de 380 hectares, sendo que o presente estudo foi realizado na área cercada, com vegetação densa e de grande porte (Figura 1). 
A Área de estudo, com extensão de cerca de 20 hectares, é de propriedade privada e destaca-se por apresentar uma marcada preservação ambiental, com vegetação típica dos biomas Cerrado e Caatinga, além de possuir figuras rupestres, pertencentes aos povos Fenícios. O clima da região é o tropical, do tipo Aw, de acordo com a classificação de Köppen-Geiger, com maior pluviosidade no verão do que no inverno, chegando a $1101 \mathrm{~mm}$ de média anual e a temperatura média da região é $27.1{ }^{\circ} \mathrm{C}$ (CLIMATE-DATA.ORG 2016).

Figura 1. Área de estudo: Bosque Sagrado da Guarita, Bom Princípio do Piauí, com destaque à área preservada e arbórea, de cerca de 20 ha de extensão.

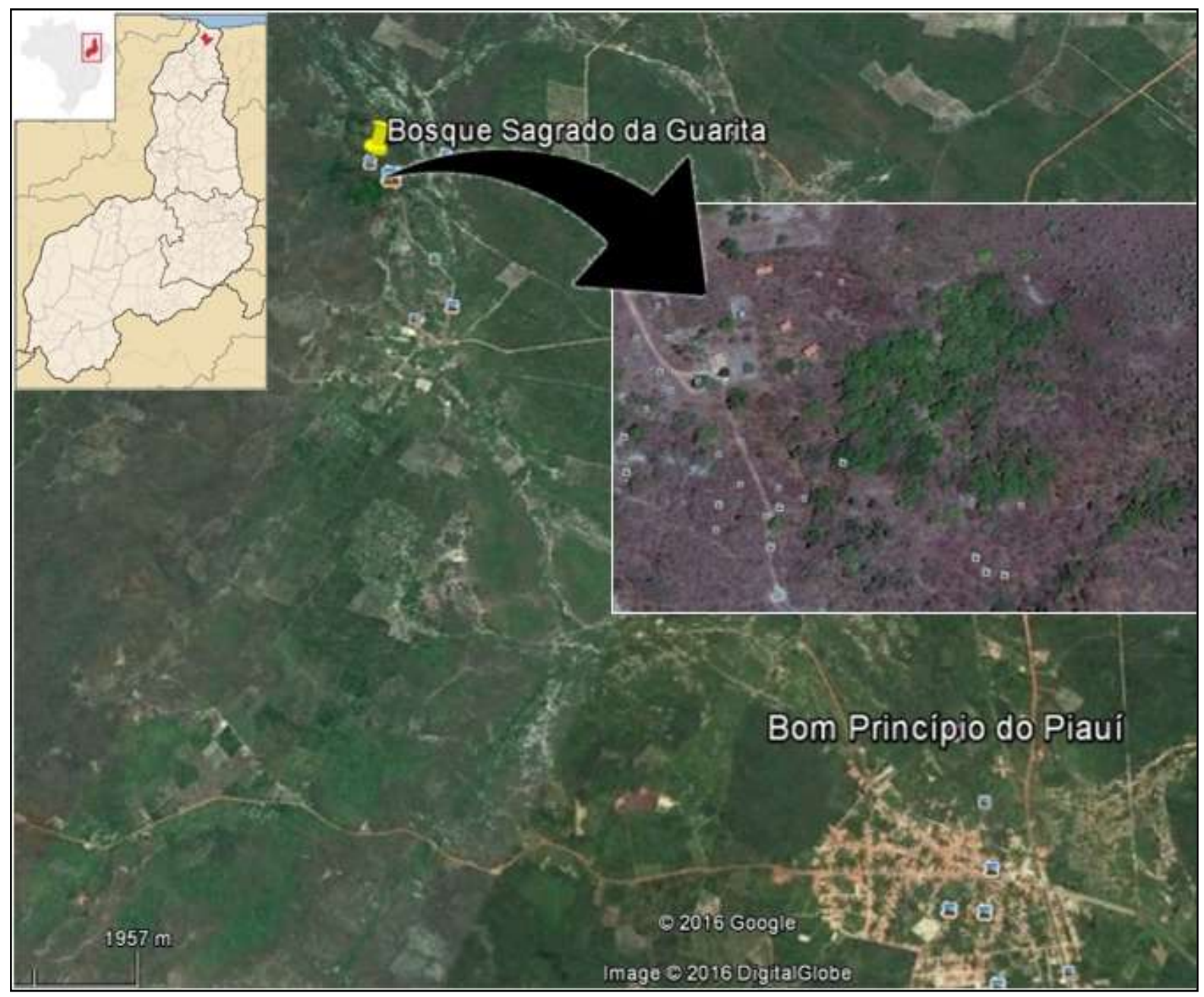

Fonte: Google Earth.

O material botânico foi obtido em cinco coletas durante o período chuvoso (fevereiro-abril) e três durante o período de estiagem, julho-setembro de 2016, totalizando oito coletas. Em todas as coletas foram investigados a presença de briófitas no solo (substrato terrícola), rocha (rupícola), caules vivos (corticícola) e em decomposição (epíxila).

As coletas do material botânico foram feitas seguindo a metodologia adotada por Yano (1989), onde as amostras foram coletadas manualmente, juntamente com parte do substrato, utilizando canivete e acondicionando-as em sacos de papel devidamente identificado com dados referentes ao local, data e tipo de substrato. 
O material coletado foi identificado em laboratório, com o auxílio de microscópio estereoscópico (lupa) e microscópio óptico. Para os cortes histológicos foram utilizadas seringas, lâminas de aço, cola branca e álcool 70\%, lâmina, lamínula e água. Para as fotografias foi utilizado câmera Sony de 8 megapixels.

Na identificação do material botânico foram utilizadas chaves de identificação, descrições de literatura especializada, além de ilustrações e fotografias. Os espécimes foram identificados adotando Yano (1992), Castro et al. (2002) Câmara (2008), Oliveira (2008), Yano e Peralta (2009), Vilas Boas-Bastos e Bastos (2009), Oliveira e Bastos (2009; 2010), Bordin (2011), Costa (2015) e confirmadas com especialistas da área de briologia.

Os dados sobre a distribuição geográfica tiveram por base Yano (1992; 1994), Pôrto et al. (1994), Pôrto e Bezerra (1996), Castro et al. (2002), Oliveira e Alves (2007), Câmara (2008), Oliveira (2008), Yano e Peralta (2009), Yano et al. (2009), Oliveira e Bastos (2009; 2010), Yano (2010), Bordin (2011), Costa (2015) e Site Flora do Brasil 2020 (em construção).

Após o estudo, o material botânico foi incorporado ao Herbário Delta do Parnaíba/HDELTA da Universidade Federal do Piauí-UFPI/Campus Ministro Reis Velloso-CMRV.

\section{Resultados e Discussão}

Das 51 amostras coletadas, foram identificados 12 táxons distribuídos em cinco famílias do filo Bryophyta e uma do filo Marchantiophyta. Dentre os 12 táxons, um consta como novo para o Piauí e outro como citação pela segunda vez, também para o estado do Piauí. Uma sinopse é apresentada abaixo, assim como chave de identificação, descrição e fotomicrografias da segunda e da nova ocorrência. * Indica nova ocorrência para o estado:

Sinopse dos táxons

\section{Archidiaceae Shimp.}

Archidium ohiense Schimp.

\section{Calymperaceae Kindb.}

Calymperes palisotii Schwägr.

Octoblepharum albidum Hedw.

\section{Fissidentaceae Schimp.}

*Fissidens amoenus Müll. Hal.

Fissidens angustifolius Sull.

Fissidens guianensis Mont. var. guianensis

Fissidens zollingeri Mont.

\section{Pottiaceae Shimp.}

Hyophiladelphus agrarius (Hedw.) R.H.Zander.

Hyophila involuta (Hook.) A.Jaeger.

\section{Stereophyllaceae W.R.Buck e Ireland}

Entodontopsis leucostega (Brid.) W.R.Buck e Ireland.

\section{Ricciaceae L.}

Riccia brasiliensis Schiffn.

Riccia fruchartii Steph.

Chave de identificação para as novas ocorrências 


\section{Fissidentaceae}

1. Gametófitos medindo mais de $7 \mathrm{~mm}$ Fissidens angustifolius

1'Gametófitos medindo até $5 \mathrm{~mm}$ $\ldots .2$

2. Limbídio em toda a lâmina, confluente com o ápice do filídio Fissidens zollingeri

2' Limbídio apenas na lâmina vaginante .3

3. Gametófitos com rizoides avermelhados, ápice do filídio mucronado a obtuso.... Fissidens guianensis var. guianensis 3' Ápice do filídio agudo a acuminado. *Fissidens amoenus

\section{Ricciaceae}

1. Talo mais alto do que largo, margem dos lobos purpura. Riccia brasiliensis

1. Talo mais largo do que alto, margem do talo hialina. Riccia fruchartii

Descrição da nova e segunda ocorrências

\section{Fissidentaceae}

Fissidens amoenus Müll. Hal., Bot. Zeitung (Berlin) 5: 38. 1847. (Figura 2).

Gametófitos pequenos, com média de altura de 3,5-4 mm, verde-claros a amarelados; filídios oblongo a oblongo-lanceolados, contíguos a distantes; ápice agudo a acuminado; margem crenulada a serreada; costa percurrente, tipo bryoides, forte, amarelada, terminando 2-4 células antes do ápice; lâmina vaginante corresponde a 2/3 ou 1/2 do filídio; limbídio presente na metade inferior da lâmina vaginante; lâmina dorsal estreitando-se até a inserção no caulídio; células hexagonais a arrendondadas, irregulares; células da base da costa curto-hexagonais a quadráticas; papilas ausentes. Esporófito terminal, seta amarelada, cápsula globosa, peristômio tipo bryoides. Substrato: rupícola. Forma de vida: flabelado, tufo.

Observação: Após retirada do filídio do caulídio, foram observadas estruturas celulares (2-3 células), hialinas, semelhantes a pelos no caulídio, localizadas no ponto de inserção.

Material examinado: Brasil, Piauí: Bom Princípio do Piauí, Bosque Sagrado da Guarita, 26.IX.2016, rocha, fértil, J. C. V. Santos, 11 (HDELTA). 
Figura 2. Fissidens amoenus: A. Aspecto geral do gametófito; B. Estrutura observada no caulídio (seta); C. Porção terminal do gametófito; D. Limbídio na lâmina vaginante (seta); E. Células da base do filídio; F. Ápice do filídio; G. Gametófito com esporófito e peristômio em destaque (seta).



Fonte: Autores.

\section{Ricciaceae}

Riccia fruchartii Steph., Bull. Herb. Boissier. 6: 330. 1898. (Figura 3).

Gametófito/talo com cheiro desagradável; talo simples a bífido ou em roseta, 4-6 mm de comprimento, 1,5 mm de largura; cor verde na porção dorsal talo; lado ventral marrom a violeta; sulco mediano baixo; escamas ventrais atingindo margens do lobo, hialina, ou violáceas com margem hialina; rizoides hialinos, talo em corte transversal 1-1,5 vezes mais larga que alto; células epidérmicas fortemente espessadas, longo retangulares; células ventrais hialinas, hexagonais; esporos vermelho-marrom, granulosos, com sulcos largos e grandes tubérculos; face distal com 8-10 aréolas, espessas e grandes. Substrato: terrícola, rupícola. Forma de vida: talosa.

Material examinado: Brasil, Piauí: Bom Princípio do Piauí, Bosque Sagrado da Guarita, 06.IV.2016, rocha, fértil, J. C. V. Santos, 7 (HDELTA). 
Figura 3. Riccia fruchartii: A. Gametófito/talo no ambiente; B-C. Aspecto geral do talo; D-E. Corte transversal do talo evidenciando células (seta); F. Esporos.
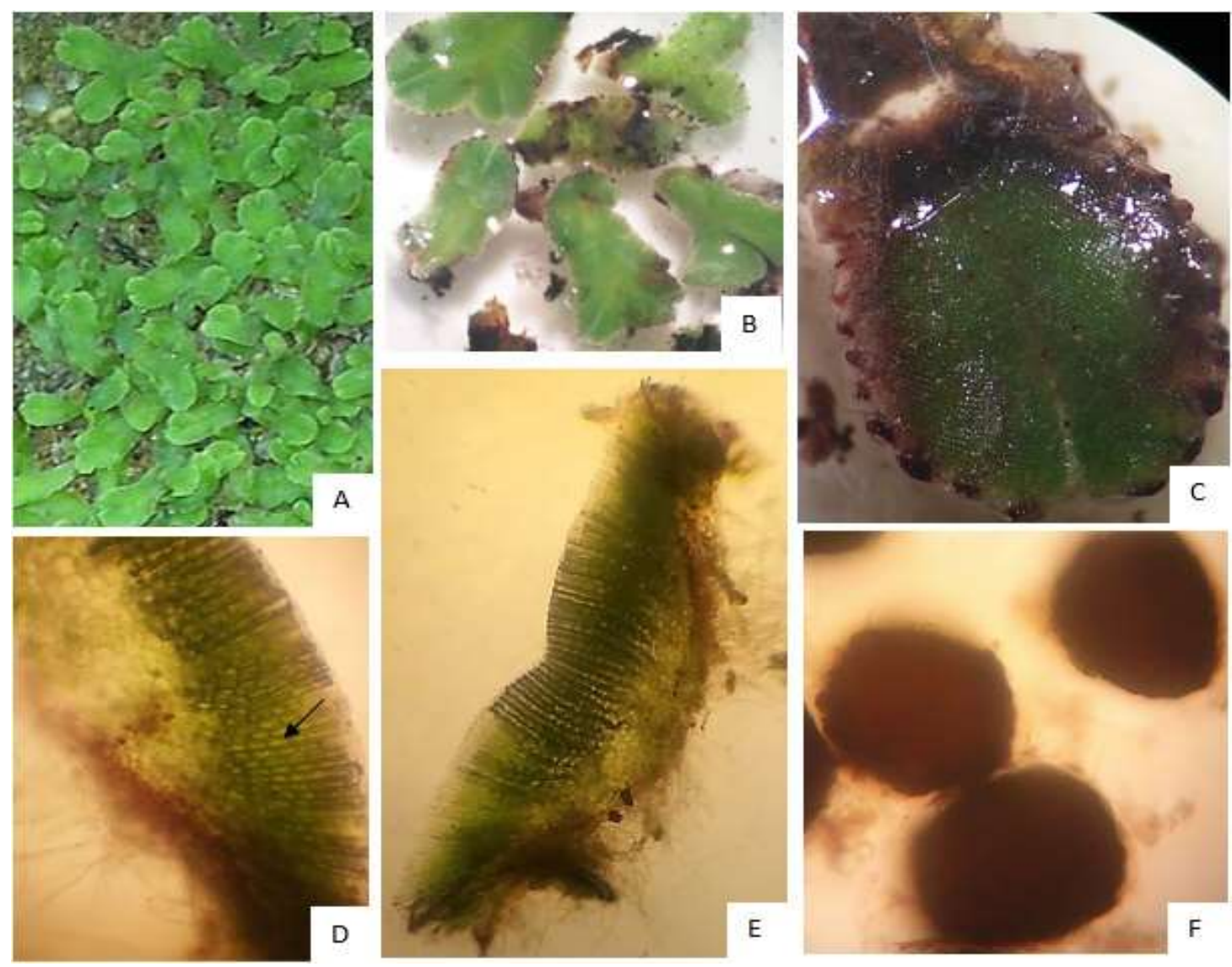

Fonte: Autores.

Na relação entre a distribuição e a abundância dos táxons observou-se maior frequência de Entodontopis leucostega em substrato rupícola, seguido de Calymperes palisotii em substrato corticícola e Riccia brasiliensis em substrato terrícola. O substrato mais representativo foi o rupícola (9 spp.), seguido do terrícola ( 2 spp.). Quanto aos táxons encontrados colonizando mais de um substrato, houve igualdade, sendo dois táxons encontrados paralelamente em substrato terrícola e rupícola e outros dois em substrato corticícola e rupícola (Figura 4). 
Research, Society and Development, v. 10, n. 5, e32710513433, 2021

(CC BY 4.0) | ISSN 2525-3409 | DOI: http://dx.doi.org/10.33448/rsd-v10i5.13433

Figura 4. Substratos colonizados por briófitas no Bosque Sagrado da Guarita, Bom Princípio do Piauí.

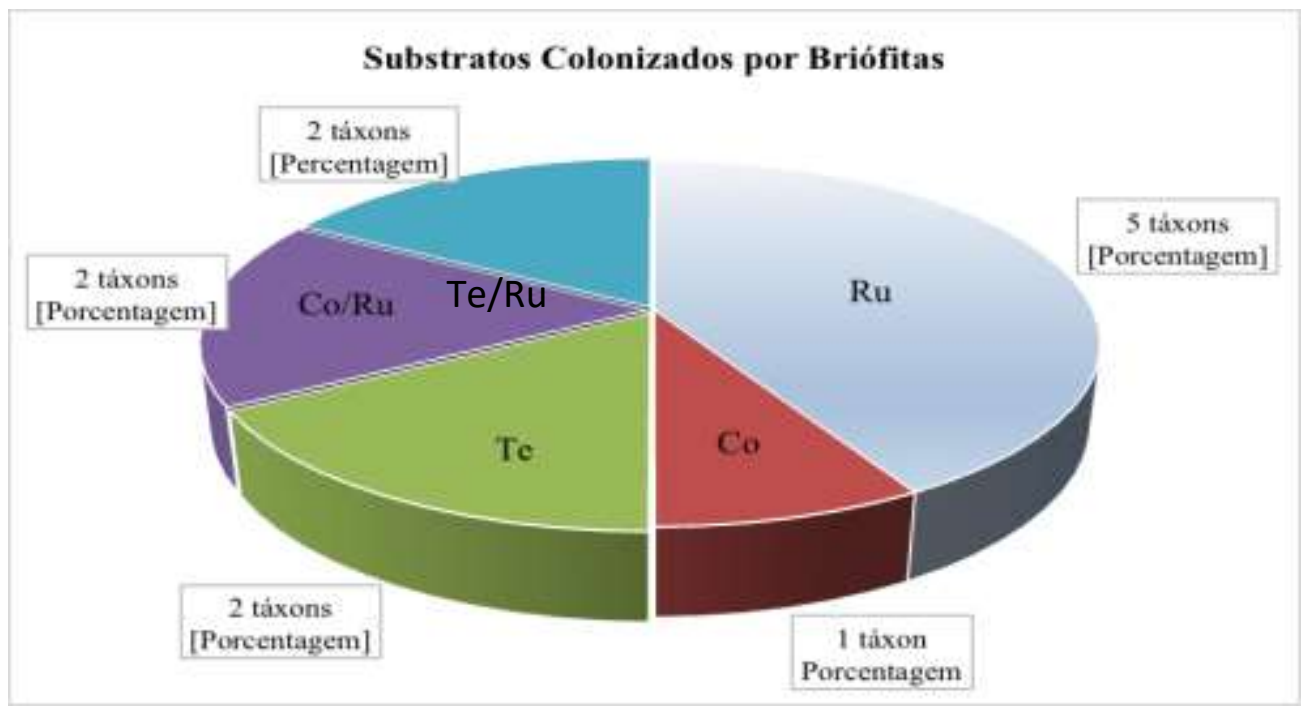

Fonte: Autores.

No aspecto da distribuição geográfica brasileira, um táxon é citado pela primeira vez para o estado do Piauí (Tabela 1), marcado com asterisco. 
Tabela 1. Relação de famílias e espécies, substratos e distribuição geográfica brasileira das briófitas do Bosque Sagrado da Guarita, Bom Princípio do Piauí - PI.

\begin{tabular}{|c|c|c|c|}
\hline \multicolumn{4}{|c|}{ Briófitas do Bosque Sagrado da Guarita, Bom Princípio do Piauí-PI, Brasil } \\
\hline \multicolumn{4}{|c|}{ Filo Bryophyta } \\
\hline Família & Táxon & Subst. & Dist. Geográfica Brasileira \\
\hline Archidiaceae & Archidium ohiense & $\mathrm{Te}$ & $\begin{array}{l}\text { AL, BA, CE, PB, PE, PI, RN, GO, } \\
\text { MS, MT, MG, RS. }\end{array}$ \\
\hline \multirow[b]{2}{*}{ Calymperaceae } & Calymperes palisotii & Co & $\begin{array}{l}\text { AM, AP, PA, RO, RR, TO, AL, } \\
\text { BA, MA, PB, PE, PI, RN, SE, } \\
\text { GO, MS, MT, ES, MG, RJ, SP, } \\
\text { PR. }\end{array}$ \\
\hline & Octoblepharum albidum & $\mathrm{Co}, \mathrm{Ru}$ & $\begin{array}{l}\text { AC, AM, AP, PA, RO, RR, TO, } \\
\text { AL, BA, CE, MA, PB, PE, PI, } \\
\text { RN, SE, DF, GO, MS, MT, ES, } \\
\text { MG, RJ, SP, PR, RS, SC. }\end{array}$ \\
\hline \multirow{4}{*}{ Fissidentaceae } & *Fissidens amoenus & $\mathrm{Ru}$ & PA, RS, SC. \\
\hline & F. angustifolius & $\mathrm{Ru}$ & $\begin{array}{l}\text { AC, AM, PA, RO, BA, CE, MA, } \\
\text { PB, PE, PI, GO, RJ, SP, RS. }\end{array}$ \\
\hline & F. guianensis var. guianensis & $\mathrm{Ru}$ & $\begin{array}{l}\text { AC, AM, PA, RO, RR, TO, AL, } \\
\text { BA, CE, MA, PB, PE, PI, MS, } \\
\text { MT, ES, MG, SP, RS. }\end{array}$ \\
\hline & F. zollingeri & $\mathrm{Ru}$ & $\begin{array}{l}\text { AC, AM, PA, RO, RR, TO, } \\
\text { AL, BA, CE, MA, PB, PE, PI SE, } \\
\text { DF, GO, MS, MT, ES, MG, RJ, } \\
\text { SP, PR, RS, SC. }\end{array}$ \\
\hline \multirow[b]{2}{*}{ Pottiaceae } & Hyophiladelphus agrarius & $\mathrm{Ru}$ & $\begin{array}{l}\text { AC, AM, PA, RO, TO, BA, CE, } \\
\text { MA, PB, PE, PI, RN, SE, DF, } \\
\text { MT, RJ, SP, RS. }\end{array}$ \\
\hline & Hyophila involuta & $\mathrm{Ru}, \mathrm{Te}$ & $\begin{array}{l}\text { AM, PA, RO, RR, AL, BA, CE, } \\
\text { MA, PB, PE, PI, DF, GO, MS, } \\
\text { MT, ES, MG, RJ, SP, PR, RS. }\end{array}$ \\
\hline Stereophyllaceae & Entodontopsis leucostega & $\mathrm{Co}, \mathrm{Ru}$ & $\begin{array}{l}\text { AC, AM, PA, RO, RR, TO, BA, } \\
\text { CE, MA, PB, PE, PI, DF, GO, } \\
\text { MS, MT, MG, RJ, SP. }\end{array}$ \\
\hline
\end{tabular}

Filo Marchantiophyta

\begin{tabular}{l|l|l|l}
\hline \multirow{2}{*}{ Ricciaceae } & Riccia brasiliensis & $\mathrm{Te}$ & $\mathrm{PE}, \mathrm{SP}, \mathrm{PR}, \mathrm{RS}, \mathrm{SC}$, PI \\
\cline { 2 - 4 } & R. fruchartii & $\mathrm{Ru}, \mathrm{Te}$ & $\mathrm{SP}, \mathrm{PR}, \mathrm{RS}, \mathrm{SC}$, PI. \\
\hline
\end{tabular}

Fonte: Autores. 
O Bosque Sagrado da Guarita apresenta uma flora briofítica bem expressiva, dada a extensão da área explorada (20 ha).

Dos 50 táxons citados, para o Piauí (Costa \& Peralta, 2015), dez ocorreram no local de estudo: Archidium ohiense, Calymperes palisotii, Entodontopsis leucostega, Fissidens angustifolius, F. guianensis. var. guianensis, F. zollingeri, Hyophiladelphus agrarius, Hyophila involuta e Octoblepharum albidum. Das Espécies de Ricciaceae, Riccia brasiliensis e $R$. fruchartii, esta última é considerada a segunda ocorrência para o Estado, e como primeira ocorrência Fissidens amoenus da família Fissidentaceae.

Comparativamente aos colaboradores Brito et al. (2008), que citaram 12 espécies para Teresina - PI, (11 Bryophyta e uma Marchantiophyta) este trabalho resulta em um número semelhante de táxons. No entanto, tal número torna-se reduzido quando comparado com o trabalho de Nascimento et al. (2020), os quais registraram 34 espécies de Bryopsida para o Parque Nacional de Sete Cidades - PI. Yano et al. (2009), em estudo das briófitas do estado do Piauí dentre outros estados do Nordeste, citaram 28 espécies e Yano (2010), em seu "Levantamento de Novas Ocorrências de Briófitas Brasileiras", citou 14 espécies para o Piauí, sendo destas 11 Bryophyta e três Marchantiophyta. Mais recentemente, Sousa et al. (2019), citaram ocorrência de 14 espécies de briófitas na Cachoeira do Bota-fora, no município de Piripiri, Piauí. Silva et al. (2019) citaram 18 espécies em seu trabalho Brioflora do Estado do Piauí: Novos Registros para a Caatinga e Cerrado. Enquanto Gomes et al. (2019) relataram o acréscimo de nove táxons no Parque Nacional da Serra da Capivara e Araujo et al. (2021) destacaram dois novos táxons para o estado do Piauí.

Com relação aos substratos colonizados, houve uma grande predominância de rupícola (41\%), seguido do terrícola (17\%) e corticícola (8\%). Espécies colonizando mais de um substrato (Ru/Te e Ru/Co) representaram 17\% (Figura 4). Os táxons comumente encontravam-se concentrados aos ambientes mais úmidos ou próximos dos locais com presença de água, tal como o entorno da cachoeira e do riacho, ocorrendo também sobre rochas e troncos de árvores.

Considerando a realização de coletas no período chuvoso e de estiagem, registrou-se uma grande redução de táxons em termos de abundância e visualização do período chuvoso para o período seco. Segundo Vitt (1981), habitats xerofíticos são frequentemente colonizados por táxons de musgos tolerantes à dessecação ou que possuem ciclo de vida curto. Tal fato foi registrado neste estudo, já que no período seco poucos táxons foram observados ou mesmo apresentavam esporófito, corroborando também com os dados de Castro et al. (2002).

O gênero mais representativo foi Fissidens (30,7\%), entretanto, destacaram-se em termos de representatividade e abundância local os gêneros Entodontopsis, Calymperes e Riccia, colonizando os substratos rupícola, corticícola e terrícola, respectivamente.

Considerando o papel bioindicador das briófitas, verificou-se que a ocorrência dos táxons na área de estudo deveu-se principalmente à grande preservação do ambiente.

Deste estudo, conclui-se que os resultados são considerados satisfatórios para a extensão da área estudada e também em razão da carência de estudos com enfoque na brioflora ocorrente no estado do Piauí. O presente trabalho fornece subsídios para estudos futuros de brioflorística e taxonomia, além da contribuição de uma primeira ocorrência, Fissidens amoenus, e pela segunda vez, Riccia fruchartii, para o estado do Piauí.

\section{Considerações Finais}

Considerando o papel biológico das briófitas, assim como sua importância como indicadores de qualidade ambiental, verifica-se que a ocorrência dos táxons na área de estudo deve-se principalmente à grande preservação do ambiente. No entanto, admitindo que o local é de propriedade privada e que há projetos em andamento visando a exploração turística, com 
implementação de pousadas no local, ressalta-se a preocupação com a preservação das espécies encontradas, afinal, a exploração local poderá resultar em impactos diretos à comunidade briofítica.

Tendo em mente os projetos de tornar o Bosque Sagrado da Guarita uma Unidade de Conservação de propriedade do Estado, tal estudo trouxe uma contribuição relevante dentro do aspecto biológico e fitogeográfico, bem como gerou dados que podem impulsionar uma nova vertente de estudos briológicos na região. Ressalta-se ainda, que os resultados foram satisfatórios para a extensão da área estudada e também em razão da carência de estudos com enfoque na brioflora ocorrente no estado do Piauí.

\section{Agradecimentos}

Os autores agradecem à Nicolas Chanove, gestor do Sitio Guarita por facilitar nas coleta e à Universidade Federal do Piauí, Campus Ministro Reis Velloso (UFPI/CMRV), pela infraestrutura para a elaboração deste trabalho.

\section{Referências}

Araujo, J., Oliveira, H. C. \& Alves, M. H. (2021). Briófitas ocorrentes no Parque Ecológico Cachoeira do Urubu, Esperantina-Piauí, Brasil, in: Lemos, J. R. (Org.) Tópicos integrados em botânica, Atena Editora, 59-74. 10.22533/at.ed.9352106016.

Bordin, J. (2011). Fissidentaceae (Bryophyta) do Brasil. Tese de Doutorado. Instituto de Botânica. 350p.

Briófitas in Flora do Brasil 2020 em construção. Jardim Botânico do Rio de Janeiro. <http://floradobrasil.jbrj.gov.br/reflora/floradobrasil/FB128472>.

Brito, E. S., Conceição, G. M., Almondes, L. M. V., Araújo, M. F. V. \& Rodrigues, M. S. (2008). Briófitas da região sudeste do município de Teresina, Piauí, Brasil. Revista Sinapse Ambiental, 18-26.

Câmara, P. E. A. S. (2008). Musgos acrocárpicos das matas de galeria da Reserva Ecológica do IBGE, RECOR, Distrito Federal, Brasil. Acta Botânica Brasílica, 22(4), 1027-1035.

Castro, N. M. C. F., Pôrto, K. C., Yano, O. \& Castro, A. A. J. F. (2002). Levantamento florístico de Bryopsida de Cerrado e mata ripícola do Parque Nacional de Sete Cidades, Piauí, Brasil. Acta Botânica Brasílica, 16(1), 61-76.

Climate-data.org. (2016). http://pt.climatedata.org/location/313660/.

Costa, D. P. (2015). Diversity and conservation of Pottiaceae (Pottiales) in the Atlantic Rainforest. Acta botânica Brasílica, 29(3), $354-374$.

Costa, D. P. \& Peralta, D. F. (2015). Bryophytes diversity in Brazil. Rodriguésia, 66(4), 1063-1071.

Gomes do Nascimento G.M., Mendes da Conceição, G., Fernandes Peralta, D. \& Oliveira H. C. (2019) Bryophytes of Serra da Capivara National Park, Piauí, Brazil. Check List 15(5), 833-845. https://doi.org/10.15560/15.5.833

Gradstein, S. R., ChurchilL, S.P. \& Salazar-Allen, N. (2001). Guide to the Bryophytes of Tropical America. Memoirs of The New York Botanical Garden, New York, 86, 1-2.

Nascimento, G. M. G., Conceição, G. M., Peralta, D. F. \& Oliveira HC (2020). Bryophytes of Sete Cidades National Park, Piauí, Brazil. Check List 16(4), 969988. https://doi.org/10.15560/16.4.969

Oliveira, H. C. \& Alves, M. H. (2007). Adições à brioflora do estado do Ceará, Brasil. Rodriguésia, 58(1), 1-11.

Oliveira, H. C. (2008). Briófitas da Chapada da Ibiapaba, Ceará, Brasil. Dissertação de Mestrado. Feira de Santana, Bahia. 212p.

Oliveira, H. C. de \& Bastos, C. J. P. (2009). Jungermanniales (Marchantiophyta) da Chapada da Ibiapaba, Ceará, Brasil. Acta Botânica Brasílica, 23(4), 12021209 .

Oliveira, H. C. de \& Bastos, C. J. P. (2010). Musgos Pleurocárpicos da Chapada da Ibiapaba, Ceará, Brasil. Acta Botânica Brasílica, $24(1)$, 193-204.

Peralta, D. F. \& Vital, D. M. (2006). Archidiaceae (Archidiales, Bryophyta) do Brasil. Boletim do Instituto de Botânica, $18,17-32$.

Porto, K. C. \& Bezerra, M. de F. de A. (1996). Briófitas de caatinga: 2. Agrestina, Pernambuco, Brasil. Acta Botânica Brasílica, 10(1), 93-102.

Pôrto, K. C., Silveira, M. de F. G. da \& SA, P. S. de A. (1994). Briófitas da caatinga 1: Estação Experimental do IPA, Caruaru - PE. Acta Botânica Brasílica, $8(1), 77-85$.

Silva, A., Oliveira, H. C. \& Conceição, G. (2019). Brioflora do Estado do Piauí: novos registros para a caatinga e cerrado. Enciclopédia Biosfera, 16, 18091820. 10.18677/EnciBio_2019A139. 
Research, Society and Development, v. 10, n. 5, e32710513433, 2021

(CC BY 4.0) | ISSN 2525-3409 | DOI: http://dx.doi.org/10.33448/rsd-v10i5.13433

Sousa, M., Abreu, G., Gomes, M. \& Oliveira, H. C. (2019). Diversidade de Briófitas da Cachoeira do Bota-Fora, Piripiri, Piauí, Brasil. In: Francisco, A. L. O. Botânica Aplicada 2, Atena Editora, 10.22533/at.ed.55119220116.

Vilas Boas-Bastos, S. B. \& Bastos, C. J. P. (2009). Musgos pleurocárpicos dos fragmentos de Mata Atlântica da Reserva Ecológica da Michelin, município de Igrapiúna, BA, Brasil: II - Hypnales (Bryophyta: Bryopsida). Acta Botânica Brasílica, 23(3), 630-643.

Vitt, D.H. (1981). Adaptive modes of the moss sporophyte. The Bryologist, 84 (2), 166-186.

Yano, O. \& Peralta, D. F. (2009). Flora de grão-mogol, minas gerais: briófitas (bryophyta e marchantiophyta). Bol. Bot. Univ. 27(1), 1-26.

Yano, O. (1989). Briófitas. In Fidalgo, O. \& Bononi, V. L., coord. Técnicas de coleta, preservação e herborização de material botânico. São Paulo, Instituto de Botânica. 62p.

Yano, O. (1992). Leucobryaceae (Bryopsida) do Brasil. Tese de Doutorado, Instituto de Biociências, Universidade de São Paulo, 318 p.

Yano, O. (1994). Briófitas da Serra de Itabaiana, Sergipe, Brasil. Acta Botânica Brasílica, 8(1), 45-57.

Yano, O. (2010). Levantamento de novas ocorrências de briófitas brasileiras. Instituto de Botânica. 253 p.

Yano, O., Bordin, J. \& Peralta, D. F. (2009). Briófitas dos estados do Ceará, Maranhão, Paraíba, Piauí e Rio Grande do Norte (Brasil). Hoehnea, $36(3)$, $387-$ 415. 